University of Nebraska - Lincoln

DigitalCommons@University of Nebraska - Lincoln

$1-26-2021$

\title{
Programmatic Foci of Women in Academic Leadership Positions at Historically Black Colleges and Universities: Intersectionality and Institutional Mission
}

Nina F. Schor

National Institute of Neurological Disorders and Stroke, nina.schor@nih.gov

Follow this and additional works at: https://digitalcommons.unl.edu/jwel

Part of the Educational Administration and Supervision Commons

Schor, Nina F., "Programmatic Foci of Women in Academic Leadership Positions at Historically Black Colleges and Universities: Intersectionality and Institutional Mission" (2021). Journal of Women in Educational Leadership. 274.

https://digitalcommons.unl.edu/jwel/274

This Article is brought to you for free and open access by the Educational Administration, Department of at DigitalCommons@University of Nebraska - Lincoln. It has been accepted for inclusion in Journal of Women in Educational Leadership by an authorized administrator of DigitalCommons@University of Nebraska - Lincoln. 
Journal of Women in Educational Leadership, 2021

doi: 10.32873/unl.dc.jwel.198

http://digitalcommons.unl.edu/jwel/

ISSN 2379-2191

Journal of

Women in

Educational

Leadership

\title{
Programmatic Foci of Women in Academic Leadership Positions at Historically Black Colleges and Universities: Intersectionality and Institutional Mission
}

\author{
Nina F. Schor, MD, PhD \\ National Institute of Neurological Disorders and Stroke \\ nina.schor@nih.gov
}

\begin{abstract}
The present studies compare, between Historically Black Colleges and Universities (HBCUs; $\mathrm{n}=102$ ) and a non-HBCU cohort matched for location, religious and vocational mission, and student enrollment (comparator CUs; $n=102$ ), the programmatic foci of women in institutional leadership positions. They demonstrate that, at HBCUs, women are more prevalent in leadership roles with male-dominated foci (e.g., finance), and less prevalent in roles with female-dominated foci (e.g., public relations) than at comparator CUs ( $p<0.01)$. A survey of academic leaders ( $n=1,053$ invited; 111 viewed survey; 83 completed survey) at these institutions indicates that women leaders at HBCUs more frequently fill institutional programmatic gaps than
\end{abstract}


their counterparts at comparator CUs ( $\mathrm{p}<0.001)$ or men in any academic setting ( $\mathrm{p}<0.005)$. Reasons may include the social purpose of HBCUs; the stereotype threat of the traditional "service" role of women and the unique intersectionality encountered by Black women faculty; and the importance of race over gender in homosociability at HBCUs. This suggests that emphasis on the socioeconomic mission and philosophy of higher education may enhance faculty recruitment diversification efforts in higher education. It also raises the question of whether seeing women in atypical leadership roles influences the career aspirations and attitudes towards women leaders of the students, both men and women, at HBCUs.

Keywords: Women academic leaders, social mission, stereotype threat, Historically Black Colleges and Universities, HBCU

\section{Introduction}

As workforce diversity is viewed increasingly as an asset in academic and health care settings, the effects of addition of women and underrepresented minority individuals to the academic and medical workforce have increasingly come under study. I have studied the programmatic foci of leadership roles played by women in academic medical schools and have noted that women overwhelmingly play roles focused on education, mentoring, image-making, and community engagement and not on policy, finance, clinical service, or research (Schor, 2018). I have also studied the research portfolios of medical schools with women or men, respectively, in the decanal research leadership position and found that women research leaders are associated with research portfolios focused on research education and training; core facilities; and community-based epidemiology research and not with basic or clinical research (Schor, 2019). In the course of the latter study, I incidentally noted that the decanal research leaders in the three Historically Black Medical Schools (HBMSs) for which such a leader is listed on the institutional website are all women. While the numbers are necessarily too small (There are only four HBMSs in the U.S.) to compare this finding with the analogous numbers for other medical schools, this unusual predominance of women research 
leaders compelled us to compare the roles of women leaders in Historically Black Colleges and Universities (HBCUs) with those of women leaders in a group of colleges and universities in the same states and with comparably sized student enrollment (comparator CUs). I hypothesized that women leaders at HBCUs occupy roles with programmatic foci related to institutional policy, finance, government affairs, legal affairs, and information technology, roles that are atypical for women leaders at comparator CUs but typical for men leaders at both HBCUs and comparator CUs. This hypothesis grew out of the historical role of HBCUs and racial minority educators in serving the needs of the communities and people around them; and the stereotypical and intersectional role of women from underserved communities in assuming even atypical responsibilities to serve these needs.

In addition, women in general have traditionally predominated in roles involving social service and caregiving (Miller, 2017) and have long served to fill gaps to keep families and workplaces "whole" (ten Brummelhuis \& Greenhaus, 2019). One study of workers in Australia demonstrated that women's job satisfaction related more to "contribution to society" and "relationship with co-workers" than did men's job satisfaction (Kifle \& Desta, 2012). For women educators from historically underserved and underrepresented communities, the relationship-based, nurturant expectations of women are compounded by the expectation of service, of giving back to and helping to elevate those communities. I therefore hypothesized that women leaders at HBCUs more frequently choose their programmatic foci to perform a service function by filling institutional programmatic gaps than women leaders at comparator CUs or men leaders at both HBCUs and comparator CUs. This hypothesis grew out of the potential for motivational synergy between and intersection of the stereotypes of (a) women as nurturers and repairers, and (b) racial minority educators as responsible for the sociopolitical and economic elevation of the minority population as a whole.

As context and background for these two hypotheses, the historically social and political roles of HBCUs and the implications of stereotype threat and intersectionality for the responsibilities of Black women educators are discussed in separate sections, below. 


\section{Background}

\section{HBCUs: History, Mission, and Philosophy}

The HBCUs had their origin in the belief of Richard Humphreys that education would provide a critical mechanism for improving the lives of Black Americans. His bequest of $\$ 10$,ooo launched the school that, 75 years later, would become Cheney University, the nation's first HBCU. In the 1860 s, during and immediately following the Civil War, several others were founded with Federal funding from the Freedman's Bureau, providing educational and professional opportunities for newly-freed slaves in the face of the restrictions of Jim Crow laws in the former Confederacy. More than providers of access to education, as the Civil Rights era dawned, HBCUs became centers for enlightenment, political action, and racial equality (Tomar, 2019).

From the time of their founding through the 1960s, HBCUs existed for the purpose of providing a college education to Black students. As other colleges and universities became racially integrated, so, too, did HBCUs. The student body of the nation's HBCUs is quite diverse and currently around $80 \%$ Black (Gasman, 2012); the faculty of these institutions is around 6o\% Black (Dawson-Smith, 2006; Strothers, 2014). While the student body of HBCUs is approximately 6o\% women (National Center for Education Statistics, n.d.), the faculty of these institutions has remained approximately 40\% women from 2001 to 2011 (Brauss et al., 2016; Renzulli et al., 2006).

HBCUs are philosophically and culturally defined by their history of dedication to social justice and their mission that encompasses, not only the welfare and future of their students, but also the interests and values of society (Center for Changing Our Campus Culture, 2017).

\section{Stereotype Threat, Women and Black Faculty, and Intersectionality}

The term "stereotype threat" describes the situation in which a negative stereotype of a particular group creates, for individuals in the group. anxiety that their performance will confirm the negative attributes to others and thereby reflect negatively on themselves and on the group as a whole (Spencer et al., 2016). Stereotype threat has 
been shown to result in underperformance in girls and women and in Black professionals in education and academic medicine (Amemiya \& Wang, 2018; Fassiotto et al., 2016; Gillenwalters \& Martinez, 2017; Laurin, 2019; Sullivan et al., 2019). Contributors to stereotype threat for women and Black professionals in education and academic medicine include outnumbering by and normative predominance of White men in both arenas (Powers et al., 2016; van Veelen et al., 2019). Contributors to stereotype threat-related underperformance include pressure to succeed on behalf of women or Black people as a group; reaction to threats to group-dependent self-identity; and environmental reinforcement of the stereotype (Spencer et al., 2016). The term "intersectionality" has its origins in critical race theory (Brookfield, 2001; Crenshaw, 1988; Mayberry, 2018; Smith et al., 2017) and refers to the oppression and marginalization borne of the intersection of multiple mainstream-subordinate characteristics (Runyan, 2018). As the term was defined by Kimberlé Crenshaw and Patricia Hill Collins and is currently used, intersectionality goes beyond structural, political, and representational identity and underlies the processes that use the structural, political, and representational framework to oppress and undermine from multiple mutually reinforcing vantage points (Agosto \& Roland, 2018). While women and Black people experience threat related to their respective stereotypes, Black women experience the confluence and synergy resulting from the intersection of these identities. For some, including many who choose careers in educational leadership, this intersectionality becomes the fuel for an "oppositional knowledge project" and a mechanism and substrate for development and deployment of transformative leadership skills (Agosto \& Roland, 2018). In the academic enterprise, transformative leadership is "bridging leadership" that enables intersectionality to be brought to bear on transformation of the interpretation and implementation of pedagogical theory towards equity and social justice for gender and racial minority populations (Fuller, 2018; Jones, 2016; Roland, 2018).

\section{Contribution of the Present Studies}

As has been shown in published meta-analytic reviews, most studies to date that examine leadership styles and motivations in men vs. 
women or Black vs. White educators consider the efficacy of leadership only at the individual and not at the group or societal level. These studies examine the leader as an individual and not as a facilitator of agency, empowerment, and innovation. As such, they represent intersectionality as a characteristic of individual identity and not as a conceptual approach and mechanism for acquiring and disseminating oppositional knowledge and achieving social justice (Agosto \& Roland, 2018; Richardson \& Loubier, 2008). As students and faculty become increasingly diverse and increasingly have multiple minority identities, there is a critical need to examine the motivations for and implications of educational leadership among those whose identities cause them to experience intersectionality as both augmenter of stereotype threat and motivator of social mission (e.g., women faculty at HBCUs, $60 \%$ of whom are Black). For this reason, as previously noted, the present studies test the hypotheses that:

(1) Women leaders at HBCUs occupy roles with programmatic foci atypical for women leaders at comparator CUs, but typical for men leaders at both HBCUs and comparator CUs; and

(2) Women leaders at HBCUs more frequently choose their programmatic foci to perform a service function by filling institutional programmatic gaps than women leaders at comparator CUs or men leaders at both HBCUs and comparator CUs.

These two hypotheses reflect and apply the overarching corollary that the roles played by women faculty at HBCUs employ intersectionality to serve the furtherance of equity, social justice, and achievement for those traditionally marginalized and oppressed.

\section{Methodology}

To test our hypotheses, I used two complementary data-gathering methods. I first examined the websites of institutions of higher education chosen for study. I subsequently administered a survey to institutional leaders identified on those institutional websites. 


\section{Study of Academic Leaders as Listed on Institutional Websites}

HBCUs that grant undergraduate degrees (HBCU Lifestyle, 2019) were identified for study. Stand-alone medical and law schools, which do not grant undergraduate degrees, were excluded from study as the organizational infrastructure and mission of such institutions differs significantly from those focusing on undergraduate education. There were therefore 102 HBCUs included in this analysis. Each HBCU was matched for location (state), size (student enrollment), public vs. private, and focus (e.g., religious, technical, community college, liberal arts) with a comparator CU. In two cases, no comparator school was identified that was a match for all four characteristics; a comparator matched for location (state), size (student enrollment), and public vs. private was assigned to each of these two HBCUs. The current President, Provost, and President's cabinet or leadership group were identified from each institution's website (accessed between 3/25/2019 and $5 / 7 / 2019$ ), and the gender of each member of this cohort was inferred from the given name, photograph, and pronoun of reference on the website, as I have previously described (Schor, 2018). The programmatic focus of each of the positions comprising each leadership group was assigned in accordance with the official title, the description of the functions of the office led by the person, and the titles of the direct reports to the person, as I have also previously described (Schor, 2018). Statistically significant independence of populations was determined using Pearson's Chi Square Test for Independence with $\mathrm{p}<0.05$ indicative of statistical significance. This statistical test was chosen because it allows testing of the null hypothesis that the nature of responses is independent of the specific faculty group to which the relevant respondents belong.

Statistically significant differences in distribution of members of populations among programmatic foci were determined using MannWhitney $U$ Test with $\mathrm{p}<0.05$ indicative of statistical significance. This statistical test was chosen because it allows testing of the null hypothesis that the rank order prevalence of the four primary reasons for choice of programmatic focus is the same for all four faculty groups. 


\section{Survey of Academic Leaders Identified from Institutional Websites}

SurveyMonkey (www.surveymonkey.com) was used to create and distribute a survey (Supplemental Table 1) to the 1,081 of the leaders in the President's or Chancellor's cabinet (hereafter termed "leaders") at HBCUs $(n=523)$ and comparator CUs $(n=558)$ identified from institutional websites whose e-mail addresses were ascertainable on their respective institutional websites. As our previous studies (Schor, 2018, 2019) had demonstrated that academic medical women leaders are more prevalent in some programmatic areas than others, but had not determined the reason for this difference, the present survey was designed to determine, for faculty at undergraduate education-focused institutions, the administrative title, primary programmatic focus, and most important reason for pursuing that focus of each survey recipient. Survey responses were received in anonymized fashion. The survey questions were as follows: (1) As what gender do you identify? (fill in the blank); (2) With what type of college or university are you affiliated? (choose 1 of 5 choices); (3) What is your current administrative title? (choose 1 of 4 choices or write in under "Other"); (4) What is the primary programmatic focus of your administrative role? (choose 1 of 11 choices or write in under "Other"); (5) Is the college with which you are affiliated a Historically Black College or University? (choose Yes or No); and (6) Which of the following statements best approximates the single most important (to you) reason you made the area you checked the primary programmatic focus of your administrative role? (choose 1 of 4 choices or write in under "Other"). This survey, response to which was voluntary and the individual responses to which are not traceable to a particular individual or institution, is exempt from full IRB review under the 21st Century Cures Act's research exemption provision in accordance with the U.S. Federal Paperwork Reduction Act.

After a single reminder sent one week after the initial invitation email containing a link to the survey, the overall survey completion rate was $83 / 88$ of those who opened the survey; this was $83 / 454$ of those who opened and 83/1,053 of those who received the invitation email (Figure 1). The average respondent took 1.65 minutes between answering question 1 and finishing the 6-question, multiple choice survey. Statistical significance of differences between groups in regard to 


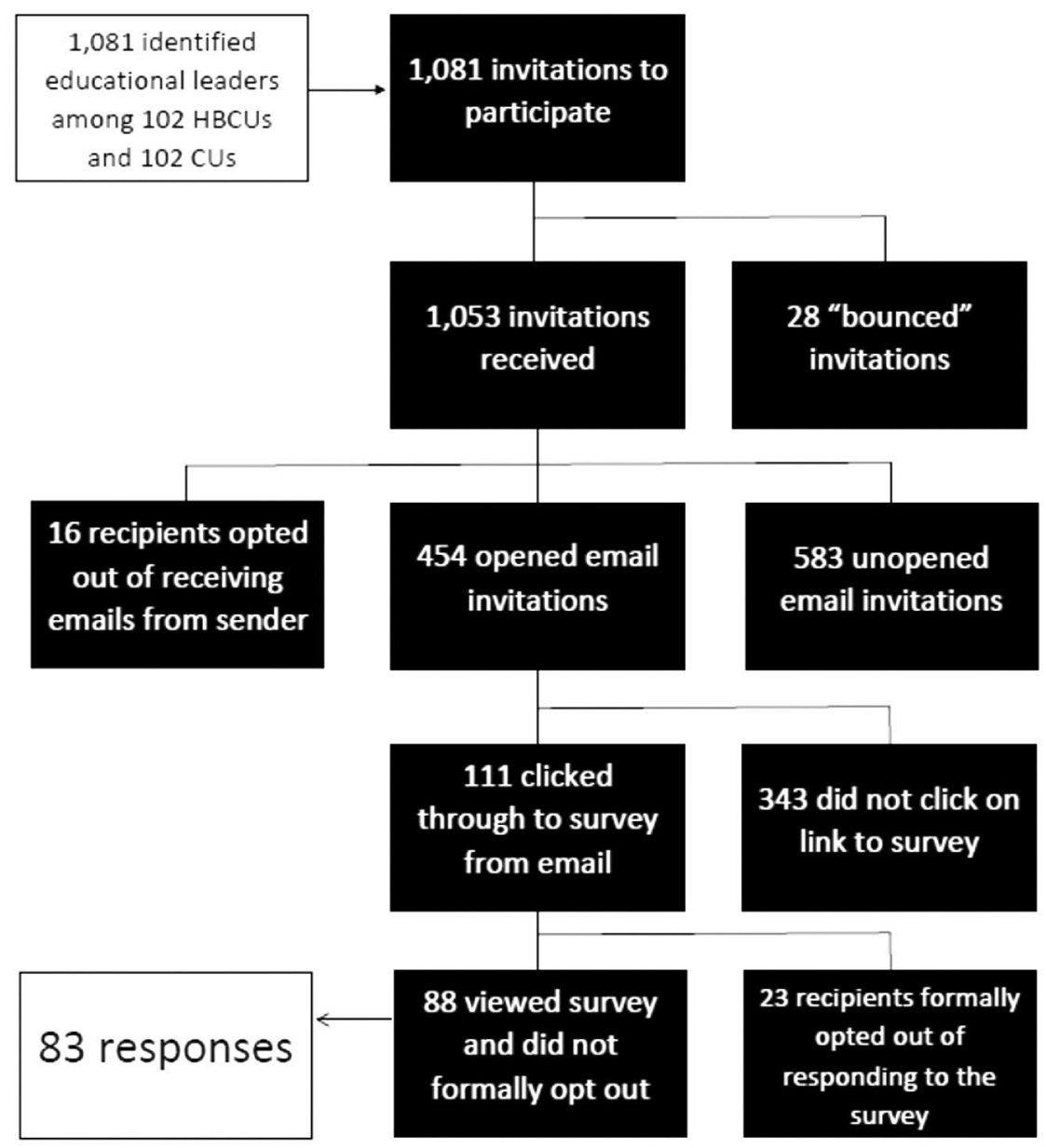

Figure 1

Flow Diagram for Administration of and Response to Survey

motivation behind choice of career focus was determined using Pearson's Chi Square Test of Good Fit, with $\mathrm{p}<0.05$ considered to be indicative of significance. This statistical test was chosen because it allows testing of the null hypothesis that the distribution of responses among the choices was the same for women leaders at HBCUs as for the other three groups. 


\section{Results}

The studies described in this section include a review of the websites of 102 HBCUs and 102 comparator CUs and a survey the link to which was sent by email to and received by 1,053 educational leaders at those 204 institutions. Each of these studies brings insights to testing of the first of the two hypotheses discussed in the Introduction. In aggregate, these two approaches provide a comprehensive assessment of this hypothesis. Testing of the second hypothesis was performed through the survey, identification of the recipients of which depended upon review of the institutional websites. In view of this, a hypothesis-based organizational structure, rather than a study methodology-based one, was chosen for this section. The characteristics of included institutions and populations, relevant to both studies, are presented first, followed by the tests and results dependent on and drawn from both studies relevant to each of the two hypotheses, respectively.

\section{Characteristics of HBCUs and Comparator CUs}

Historically Black stand-alone medical and law schools were excluded from this study as they do not grant undergraduate degrees, and all 204 HBCU and comparator CU schools included offered an undergraduate, two- or four-year education. There was no significant difference between the HBCU and comparator CU cohorts with respect to public vs. private; religious affiliation; 2 vs. 4 year degree granting; or gender distribution (Supplemental Table 2). While the student body of HBCUs is $76 \%$ Black, that of other colleges and universities in the US is $14 \%$ Black (National Center for Education Statistics, 2020).

\section{Characteristics of Respondents to the Survey}

The characteristics of respondents to the survey $(n=83,82$ of whom specified their gender) are shown in Table 1. Among respondents who specified their gender, men at religious HBCUs relative to women; men Presidents/Chancellors of HBCUs and comparator CUs are also overrepresented relative to women in that role. There are no other significant differences between the subgroups of respondents noted in the tabulated data. 
Table 1

Characteristics of Survey Respondents who Specified Gender $(n=82)$

$\begin{array}{cccc}\text { Men } & \text { Women } & \text { Men. } & \text { Women. } \\ \text { HBCU } & \text { HBCU } & \text { Compar CU } & \text { Compar CU } \\ (\mathrm{n}=12) & (\mathrm{n}=12) & (\mathrm{n}=29) & (\mathrm{n}=29) \\ \text { Number }(\%) & \text { Number }(\%) & \text { Number }(\%) & \text { Number }(\%)\end{array}$

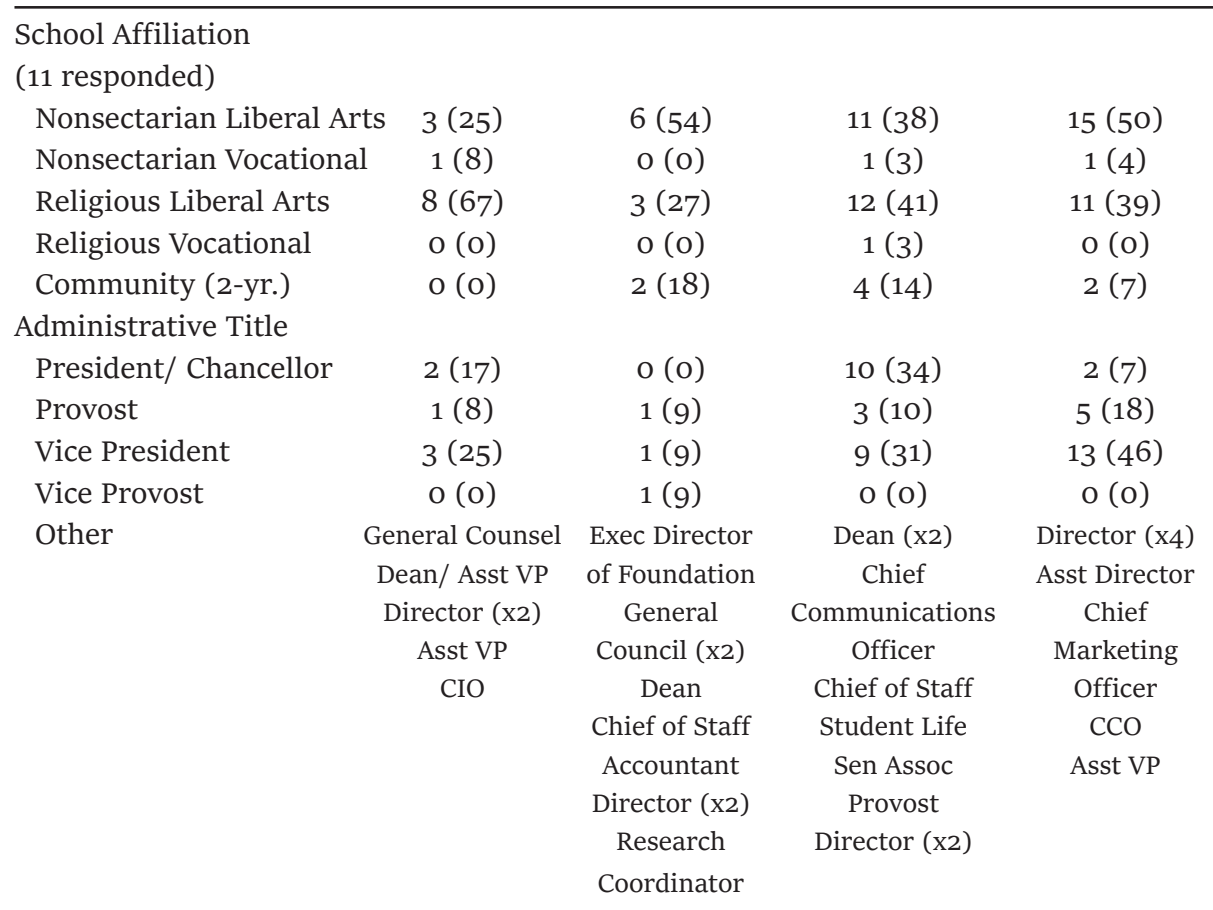

Note: $\mathrm{n}=82 ; 8 \%$ of all invitation email recipients, $18 \%$ of recipients who opened invitation email, and $94 \%$ of email openers who clicked on survey link.

\section{Testing of Hypothesis 1: Differential Prevalence of Women Leaders in Programmatically Different Leadership Roles}

Testing of this hypothesis benefitted from both study methodologies. As such, the results both of mining of institutional websites and of administration of a survey to institutional leaders are presented in each of the subsections below. 
Prevalence of Women in Leadership Roles with a Specific Focus at HBCUs and Comparator CUs.

\section{Classification of Academic Leaders from Listing on Institutional} Websites. As has been previously described for academic medical institutions, this study of college and university faculty divided the programmatic foci of academic leadership roles into four categories: general leadership; governance and finance; education and training; and image-making (Schor, 2018). Table 2 presents data from institutional websites and shows the percent of the occupants of leadership positions with particular programmatic foci who are women. The table compares HBCUs with comparator CUs in this regard. In general, women are more prevalent in leadership roles at HBCUs than at comparator CUs. Although most leadership positions focused on governance and finance are occupied by men, women predominate at HBCUs in positions related to institutional strategy. Women are well-represented in legal leadership (i.e., general counsel) at both HBCUs and comparator CUs.

\section{Self-classification from Survey of Academic Leaders Identified from} Institutional Websites. Figure 2B demonstrates concordance of the survey data on prevalence of women in leadership roles focused on governance and finance and on education and image-making with the website-determined data shown in Figure 2A. In addition, in both the website- and survey-based studies, I noted a trend for women to be more prevalent at HBCUs than at comparator CUs in positions focused on governance and finance.

Although the aggregated populations depicted in Figures $2 \mathrm{~A}$ and $2 \mathrm{~B}$ are not quite statistically independent from one another, the figure again suggests, as is demonstrated in the parsed data in Table 2, that women are more highly represented in most general and government/finance leadership roles at HBCUs than at comparator CUs. In contrast, with the exception of Community Affairs and Institutional Effectiveness, women seem to be equally represented in education/training and image-making at HBCUs and comparator CUs. 
Table 2

Prevalence of Women in Specific Roles at Historically Black Colleges and Universities ( $\mathrm{HBCU}$ ) and Comparator Colleges and Universities (Comparator CU)

\begin{tabular}{|c|c|c|}
\hline & \multicolumn{2}{|c|}{ \% Women in Leadership Role } \\
\hline & HBCU & Comparator $\mathrm{CU}$ \\
\hline \multicolumn{3}{|l|}{ GENERAL LEADERSHIP } \\
\hline Category Total (Fraction) & $26(27 / 106)$ & $22(22 / 102)$ \\
\hline President & 26 & 22 \\
\hline \multicolumn{3}{|l|}{ GOVERNANCE/FINANCE } \\
\hline Category Total (Fraction) & $44(47 / 107)$ & $36(37 / 103)$ \\
\hline Finance & 34 & 32 \\
\hline Information Technology & 30 & 23 \\
\hline Strategy & 80 & 50 \\
\hline Government Relations & 25 & o \\
\hline Legal & 75 & 65 \\
\hline \multicolumn{3}{|l|}{ EDUCATION/TRAINING } \\
\hline Category Total (Fraction) & $47(69 / 169)$ & $45(67 / 150)$ \\
\hline Provost & 51 & 44 \\
\hline Student Affairs & 43 & 47 \\
\hline Institutional Effectiveness & 66 & 37 \\
\hline \multicolumn{3}{|l|}{ IMAGE-MAKING } \\
\hline Category Total (Fraction) & $55(59 / 108)$ & $59(77 / 131)$ \\
\hline Marketing/Communications & 53 & 67 \\
\hline Human Resources & 88 & 79 \\
\hline Community Affairs & 56 & 18 \\
\hline Advancement & 58 & 52 \\
\hline
\end{tabular}

Note: Schools were matched for location (state), size (student enrollment), and focus (e.g., religious, technical, community college, liberal arts). Data were ascertained from institutional websites as described in the text. Differences in aggregated major categories between HBCUs and Comparator CUs did not reach statistical significance (Pearson's Chi Square Test for Independence). 
A

$$
60
$$

A

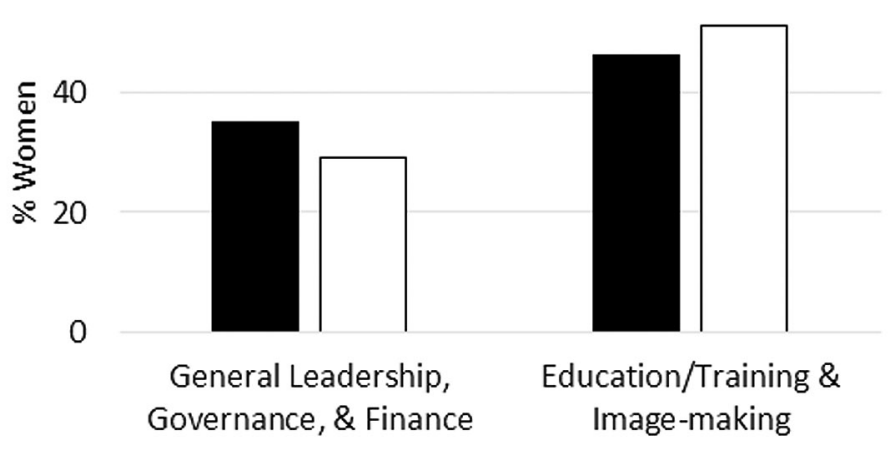

B 80

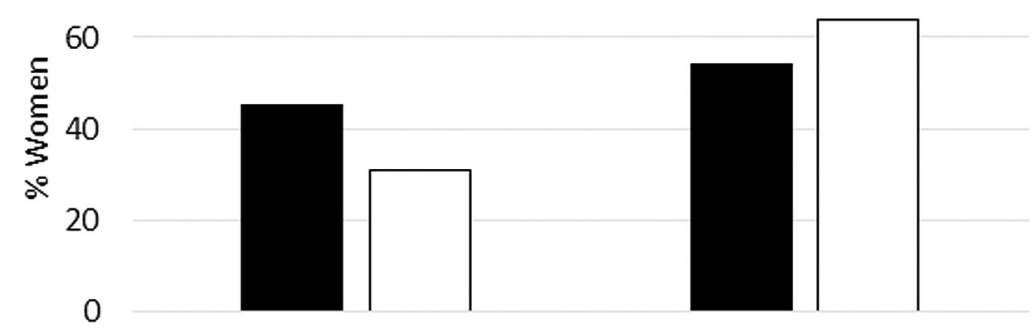

General Leadership,

Governance, \& Finance

Education/Training \& Imagemaking

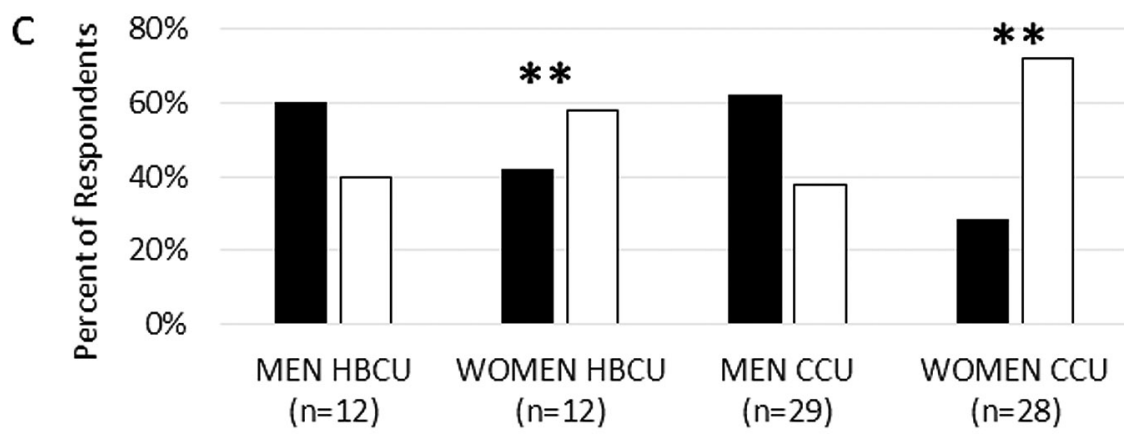

Respondent Gender and Type of Institution of Affiliation 


\section{Figure 2}

(A,B) Prevalence of Women among Individuals in Leadership Positions with Various Programmatic Foci; (C) Percent of Respondents to a Survey Distributed to Academic Leaders $(n=1,081)$ in Roles with each of Two Programmatic Foci

Note: For (A,B), programmatic classification of leadership positions was performed as previously described (Schor, 2018). Differences between HBCUs and comparator CUs (CCU) in each programmatic category did not attain statistical significance in this small sample (Pearson's Chi Square Test for Independence). $\square$, HBCUs; $\square$, comparator CUs. For (A), data were obtained on academic leadership from institutional websites for $102 \mathrm{HB}-$ CUs and 102 comparator CUs. For (B), data were obtained on academic leadership from respondents to a survey as described for the next panel. For (C), the survey response rate was $83 / 1,081$ of all to whom the survey was sent, $83 / 454$ of those who opened the survey invitation email, and $83 / 88$ of those who clicked on the emailed link to the survey; one respondent did not answer this question. **Women (HBCU + comparator CU) differ from men (HBCU + comparator CU) with $\mathrm{p}<0.01$; Pearson's Chi Square Test for Independence. CCU denotes comparator CU. Differences between HBCU and CCU overall or for men or women alone did not attain statistical significance in this small sample. $\mathbf{0}$, General Leadership, Governance, and Finance; $\square$, Education/Training and Image-making.

Prevalence of Specific Programmatic Foci of Leadership Roles in Women at HBCUs and Comparator CUs.

\section{Classification of Academic Leaders from Listing on Institutional Web-} sites. Figures $2 \mathrm{~A}$ and $2 \mathrm{~B}$ examine the percent of leaders in a given programmatic area that are women; I also examined the percent of women leaders who focus on a given programmatic area. In data inferred from individual professional titles and role descriptions on institutional websites, there were 248 women ( $47 \%$ of total) found to occupy major leadership roles in HBCUs. $68 \%$ of them were in education/training and image-making roles. There were 203 women ( $42 \%$ of total) found to occupy major leadership roles in comparator CUs. $71 \%$ of them were in education/training and image-making roles. According to data accrued 
from institutional websites, the percent of women who pursue roles focused on education/training and image-making does not differ significantly between HBCUs and comparator CUs.

\section{Self-classification from Survey of Academic Leaders Identified from} Institutional Websites. I also mined data accrued from our survey of the institutional leaders identified from institutional websites (Figure 2C; Table 3). Note that this dataset differs from the website data both in that it accounts for those invitation email recipients $(n=1,053)$ who opened the invitation ( $43 \%$ of invitees), clicked on the survey link $(24 \%$ of email openers), did not formally opt out of participation $(79 \%$ of survey viewers), and responded to the survey ( $94 \%$ of survey viewers who did not opt out of participation, or $8 \%$ of the recipients of the invitation email) and that the respondents themselves identified their own primary area of focus, rather than focus being inferred from professional title and website description of professional role. Statistical analysis of the data in Table 3 demonstrates that the higher fraction of women leaders at HBCUs who are focused on general leadership, governance, and finance differs significantly from that at comparator CUs ( $p$ $<$ 0.05; Mann-Whitney U Test); and the lower fraction of women leaders at HBCUs who are focused on education/training and image-making differs significantly from that at comparator CUs ( $p<0.01$; MannWhitney U Test).

\section{Testing of Hypothesis 2: Motivating Factors for Choice of Professional Focus}

\section{Survey of Academic Leaders Identified from Institutional Websites.}

Figure 3 depicts the responses of the four survey respondent subgroups to the request to identify the primary personal motivator for choice of a particular primary programmatic focus (i.e., survey question 6). Consistent with our hypothesis, women in leadership roles at HBCUs cite filling a gap identified by institutional leadership as the primary reason for their choice of programmatic focus more frequently than women at comparator CUs ( $p<0.001$, Pearson's Chi Square Test of Good Fit) or men at either type of institution $(\mathrm{p}<0.005)$. Men cite passion, talent, and 
Table 3

Primary Programmatic Focus as Identified by Respondents to the Survey

\begin{tabular}{|c|c|c|c|c|}
\hline & $\begin{array}{c}\text { Men } \\
\text { HBCU } \\
(\mathrm{N}=12)\end{array}$ & $\begin{array}{c}\text { Women } \\
\text { HBCU } \\
(\mathrm{N}=13)\end{array}$ & $\begin{array}{c}\text { Men } \\
\text { CCU } \\
(\mathrm{N}=29)\end{array}$ & $\begin{array}{c}\text { Women } \\
\text { CCU } \\
(\mathrm{N}=29)\end{array}$ \\
\hline General, Policy, Finance & $50 \%$ & $54 \%$ * & $66 \%$ & $28 \%$ \\
\hline General & 1 & $\mathrm{o}$ & 12 & 2 \\
\hline Research & 1 & 1 & 2 & 2 \\
\hline Finance & 1 & 2 & 3 & $\mathrm{O}$ \\
\hline Policy/Government Relat. & 1 & $\mathrm{o}$ & 1 & 2 \\
\hline Information Technology & 1 & $\mathrm{o}$ & 1 & 2 \\
\hline Legal & 1 & 2 & o & o \\
\hline Data Analysis & $\mathrm{O}$ & 2 & o & $\mathrm{o}$ \\
\hline Education, Image-making & $50 \%$ & $46 \%$ ** & $34 \%$ & $72 \%$ \\
\hline Education & 2 & o & 4 & 2 \\
\hline Faculty Affairs & $\mathrm{O}$ & 3 & o & 2 \\
\hline Pub. Relat./Commun. Aff. & 1 & $\mathrm{o}$ & 3 & 3 \\
\hline International Relations & $\mathrm{o}$ & $\mathrm{o}$ & o & $\mathrm{o}$ \\
\hline Diversity/Inclusion & $\mathrm{o}$ & $\mathrm{o}$ & o & 2 \\
\hline Marketing & $\mathrm{o}$ & o & 2 & 3 \\
\hline Advancement & 1 & $\mathrm{o}$ & 1 & 3 \\
\hline Human Resources & 1 & $\mathrm{o}$ & o & 1 \\
\hline Academic Affairs & 1 & 1 & $\mathrm{o}$ & 1 \\
\hline Communications & $\mathrm{O}$ & 1 & $\mathrm{o}$ & $\mathrm{o}$ \\
\hline Student Affairs & o & 1 & o & 3 \\
\hline Educational Accreditation & $\mathrm{o}$ & $\mathrm{o}$ & $\mathrm{o}$ & 1 \\
\hline
\end{tabular}

Note: Numbers in the table signify the number of individuals who identified a particular programmatic focus as the primary one in their career in response to survey question 4. Some respondents filled in the "Other" choice with foci that are explicitly listed in the table but not in the survey. *The association of women faculty at HBCUs with General, Policy, and Finance related positions is higher than and the distribution among those positions differs from that of women faculty at CCUs ( $\mathrm{p}<0.05$; Mann-Whitney U test); **The association of women faculty at HBCUs with Education and Image-making related positions is lower than and the distribution among those positions differs from that of women faculty at CCUs $(\mathrm{p}<0.01)$. 


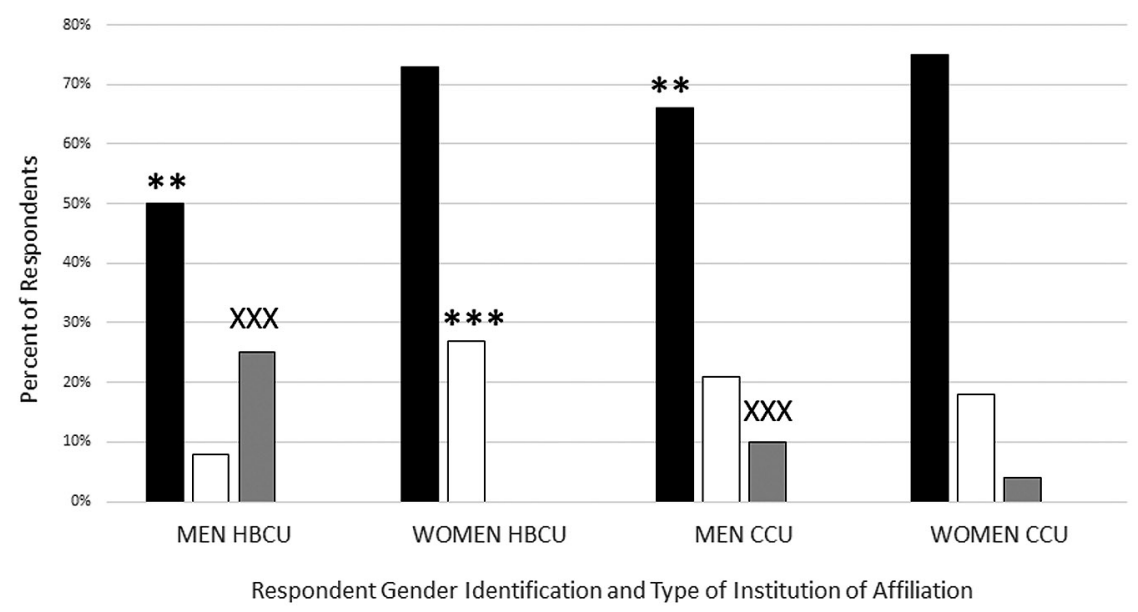

\section{Figure 3}

Reasons Given by Survey Respondents $(n=78)$ for Choice of Programmatic Focus of Administrative Career Activities

Note: The 78 respondents to the survey constitute the $8 \%$ of survey recipients who did not officially opt out of responding to the survey. ${ }^{* *}$, differs from women at comparator CUs with $\mathrm{p}<0.001$ and from men at either type of institution with $\mathrm{p}<0.005$, Chi Square Test for Goodness of Fit; **, men differ from women overall with $\mathrm{p}<0.01$; ${ }^{\mathrm{xx}}$, men differ from women overall and men at HBCUs differ from men at comparator CUs with $\mathrm{p}<0.001$. CCU denotes comparator CU. $\square$, passion/talent/training; $\square$, filling a need; $\square$, fits into lifestyle; 目, consonant with gender expectations.

training for their programmatic focus less frequently than do women ( $\mathrm{p}<0.01$ ). Surprisingly, men, and particularly those at HBCUs, cite the ability to combine their chosen programmatic focus with the lifestyle factors that are important to them more frequently than women (men vs. women, $\mathrm{p}<0.001$; men at HBCUs vs. men at comparator CUs, $\mathrm{p}<$ o.001). Neither men nor women cited the prevalence of individuals who identify as the same gender as they in their chosen programmatic focus as a reason for its choice.

$62 \%$ of women who cited filling a gap identified by institutional leadership as the primary reason for their choice of programmatic focus 
occupied positions in general leadership, policy, and finance, areas typically assigned to men; in contrast, only $43 \%$ of men who cited filling a gap identified by institutional leadership as the primary reason for their choice of programmatic focus occupied positions in education and image-making, areas typically assigned to women. For leaders at HBCUs, the analogous numbers were $33 \%$ for women and o\% for men; for leaders at comparator CUs, the analogous numbers were $80 \%$ for women and $50 \%$ for men. This suggests that the reason that women at HBCUs more frequently occupy positions of a focus typically assigned to men than do their counterparts at comparator CUs is that a higher fraction of women at HBCUs are called upon or choose to fill an institutional gap, and not that they are in an environment intrinsically more conducive to women accepting roles in male-dominated areas of focus. Furthermore, that women at HBCUs are more frequently filling a gap than their male counterparts is not likely the result of a relative paucity of men in leadership at such institutions. Among leaders at HBCUs, men constituted $53 \%$ of recipients of and $50 \%$ of respondents to the survey.

\section{Discussion}

Previous studies of faculty leaders in academic institutions have demonstrated the stereotyping of women leaders as collaborative, nurturing, and relationship-driven and men leaders as agentic, competitive, and individual achievement-driven (Bismark et al., 2015; Eagly \& JohannesenSchmidt, 2001; Garcia-Ael et al., 2018; Richardson \& Loubier, 2008; Schor, 2018). Other studies have suggested that, in academic medical institutions, women focus their leadership on education and institutional image-making, while men focus their leadership on finance and policy (Schor, 2018, 2019). Studies that compare HBCUs with other CUs have noted the focus of HBCUs on community mission and achievement of social justice as a differentiator between the two sets of institutions (Center for Changing Our Campus Culture, 2017; Tomar, 2019). In our previous work on medical schools, I have noted the unusually high prevalence of women leaders in programmatic areas typically ascribed to men at HBMSs (Schor, 2019). These areas include institutional policy and strategy, finance, clinical service leadership, and research leadership. This 
observation could not easily lead to rigorous hypothesis testing or determination of the relevant mechanisms in the HBMS sphere, as there are only four HBMSs in the U.S. The present study tests two related hypotheses at HBCUs and comparator CUs matched for location, size, and type of school. It uses data accrued from institutional websites and from a survey administered to institutional leaders identified from those websites to test the hypotheses that: (a) women leaders at HBCUs occupy roles with programmatic foci atypical for women leaders (i.e., institutional policy, finance, government affairs, legal affairs, research, and information technology) at comparator CUs but typical for men leaders at both HBCUs and comparator CUs; and (b) women leaders at HBCUs chose their programmatic foci to perform a service function by filling institutional programmatic gaps more frequently than women leaders at comparator CUs or men leaders at both HBCUs and comparator CUs.

As regards the first hypothesis, two previous studies have suggested that, at HBMSs, women are more prevalent in department chair and decanal research leadership role than at other medical schools (Mader et al., 2016; Schor, 2019). The present study demonstrates (Table 2) that, at HBCUs, women are more prevalent in leadership roles focused on governance and economics and less prevalent in such roles focused on education and image-making than at comparator CUs. Furthermore, it confirms our finding for academic medical institutions in colleges and universities in general that women overall are less prevalent in leadership roles focused on governance and economics and more prevalent in such roles focused on education and image-making than men (Figures $2 \mathrm{~A}$ and $2 \mathrm{~B}$ ).

Why HBCUs and their medical school counterparts would have greater prevalence than comparator schools of women in leadership roles atypically occupied by women is not clear. It has been suggested that women rise to the rank of department chair more frequently in Historically Black Medical Schools than other medical schools because "otherness" is more readily accepted in the former than the latter and, therefore, women pursue leadership roles more frequently in the former than the latter (Mader et al., 2016). It has also been noted that Historically Black Medical Schools have more robustly embraced the notions of positive impact on the community, elevating the educational and professional status of the next generation, and leaving a legacy (Rodriguez et 
al., 2017), notions that have been found to frequently underlie pursuit of leadership positions by women (Hannum et al., 2015). Indeed, interviews with women presidents of HBCUs underscore the importance of socioeconomic mission in their decision to pursue leadership (Mathewson, 2017). Although the specific reasons for their importance may have changed somewhat with societal evolution, HBCUs have always served an overarching social and community-focused mission (Gasman et al., 2017; Henderson et al., 2019; Lomax, 2006).

One study from the UK noted that "homosociability" - the tendency to choose people like oneself - is a driver of choice of particular individuals as leaders (Shepherd, 2017). It may be that, at HBCUs, homosociability involves Blackness, making gender less important than at comparator CUs (Smith et al., 2017). Indeed, it could be said that intersectionality at HBCUs pertains most to White women, who are nonmainstream in a majority Black, majority men environment (DawsonSmith, 2006; Strothers, 2014).

It is interesting that, in our studies of the fraction of women in each cohort of schools who pursue particular programmatic foci, I obtained discordant results between the website and the survey methodology. The survey methodology identified a significant difference between women at HBCUs and their counterparts at comparator CCUs (Table 3), while the website methodology found the two groups comparable (Figure $2 \mathrm{C}$ ). The discrepancy likely reflects fundamental differences in what is being examined and from whom information is being obtained between the two methodologies. The website methodology depends on inference of programmatic focus from position title and description of the role of the faculty member and/or the related institutional office. The survey methodology obtains the primary programmatic focus of each individual from that individual herself. On the other hand, the survey methodology entails the selection bias that resulted from the need to open the invitation email, click on the survey link, and complete the survey, and the potential for stereotype threat to influence what women at each kind of institution are comfortable saying "publicly" is their primary focus (Laurin, 2019); feeling the "double" stereotype threat of intersectionality (van Veelen et al., 2019), perhaps the predominantly Black women at HBCUs were more likely than predominantly White women at comparator CUs to respond in a way that counteracts their stereotypical career focus. 
As regards the second hypothesis, the prevalence of particular driving forces for their choice of programmatic focus differs between women at HBCUs and the other faculty groups and between men and women in general, as well. Our results suggest that institutional need more frequently drives choice of programmatic focus for women leaders at HBCUs than for their counterparts at comparator CUs and men from both types of institutions. While this finding fits well with the intersectionality and bridging leadership of women who choose to work at HBCUs (Richardson \& Loubier, 2008; Roland, 2018), it must be viewed with caution through the lens of potential selection bias of those who chose to respond to our survey.

A focus group-based study of Black and White women's experiences and perceptions of "womanhood" (Settles et al., 2008) revealed that, while White women tend to interpret such experiences as attributable to gender alone, Black women interpret many of them as attributable to the coincidence of gender and race. Both Black and White women experienced gender-based mistreatment and sexual harassment and both noted the rewarding and burdensome aspects of childcare, but Black women spoke disproportionately of caretaking as a responsibility and challenge. Only White women discussed the advantages of acceptability for women of showing emotions and of being protected and shown curtesy by men; only Black women discussed family role models and development of "inner strength" and self-reliance. Both Black and White women spoke of the positive aspects of close friendships with other women, but Black women also emphasized the sense of competition, tendency towards gossip and betrayal of confidence, and burden of the expectation of unconditional loyalty. Only white women portrayed the balancing of family and career as a choice; Black women uniformly spoke of the expectation of and financial need for doing both and the conflict that grows out of the lack of choice. Black and White women therefore share the experience and perception that being a woman implies susceptibility to gender-based mistreatment and the joys of caretaking. But there are additional layers on top of this perception resulting from the intersectionally unique implications of being a Black woman. These imply fulfilling duty and familial and societal expectations and leveraging the early life acquisition of inner strength and self-reliance. It is perhaps these attributes of "Blackwomanhood" that compel and equip 
Black women faculty to teach at HBCUs and to take on responsibilities often assigned, at comparator CUs, to men.

Regardless of the factors that contribute to the relative prevalence of women in programmatically atypical leadership roles at HBCUs, students and faculty at these institutions likely experience a different leadership landscape with respect to gender than their counterparts at nonHBCU institutions. Given that HBCUs train $23 \%$ of US African-American college graduates, $50 \%$ of US African-American teachers, and $40 \%$ of US African American health professionals; and confer $40 \%$ of all STEM degrees and $60 \%$ of engineering degrees earned by African-American students in the US (Black Student Achievement Program, 2015), the impact of such an environment has the potential to make a significant impact on the future professional community. It remains for future studies to determine the effects on future professionals of early career exposure to an environment in which women may be drawn to and accepted in leadership positions because of the overarching social mission and vision of those institutions. Similarly, it will be important to explore the mechanisms of and effects on future professionals of early career exposure to an environment in which men choose their career paths in consideration of "lifestyle" factors - a consideration traditionally ascribed to women.

The value of exploration of these questions raised by the present studies lies in its potential to serve as a model for building acceptance in other environments of leadership positions by women and of women in leadership positions by their largely male counterparts. While HBCUs have struggled financially and some have questioned their importance and relevance in a post-slavery US (Stuart, 2012), there are perhaps lessons in the power of systematic inclusion, service, and work-life balance to be learned and translated to majority environments from these social mission-driven institutions.

\section{Limitations of the Present Studies: Implications for Future Work}

The studies described in this paper are aimed at beginning to identify and discern the reasons for the differences in the professional foci pursued by women faculty at HBCUs and other faculty at HBCUs and comparator CUs. They employ both web-based and direct survey ascertainment. As detailed below, each of these methodologies has limitations and 
neither alone affords conclusive testing of the two hypotheses proposed. It is in the synergistic confluence of these two methodologies that the relevant null hypotheses can convincingly be rejected.

First, the present studies identify from institutional websites the genders of leaders at each school. Websites are not uniformly and systematically kept up-to-date and accurate. Furthermore, the discernment of gender from name, photograph, and pronoun descriptors is not reliably accurate or complete and does not always allow for non-binary designations. The matching of comparator CUs to HBCUs was done on the basis of location (state), size (student enrollment), public vs. private, and focus (e.g., religious, technical, community college, liberal arts). There are other factors, including the demographics and socioeconomic status of the students and surrounding community and the financial status of the school, that were not considered and may be discrepant between "matched" institutions and may influence the nature and mission of leadership positions represented in each institution's Presidential cabinet.

Second, I surveyed leaders identified on institutional websites whose e-mail addresses were obtainable on the Internet, whether from institutional websites or directories or via Internet browser search. The survey was sent to recipients through SurveyMonkey without prior announcement and its completion would be of no direct benefit to those who completed it. As such, the response rate was $18 \%$ of those who opened the email clicked on the link to the survey and $94 \%$ of the $79 \%$ who did not explicitly opt out of the survey completed and submitted it. There may have been a selection bias for those who chose to complete it, although they spanned all the categories of gender and school affiliation seen in the initial population. Although the survey invitation message made it clear that the individual responder's identity, e-mail, and specific school affiliation could not be linked to the response, some recipients may have been wary that this was indeed the case. The investigator requesting completion of the survey (N.F.S.) was identified by name and her e-mail address was explicitly provided to recipients of the invitation. It is possible that some responses may have been influenced by the respondent's discovery that the "evaluator" of the responses obtained was a White woman. I think this unlikely based on the work of Laurin (2019) showing that the identity of the evaluator did not influence perception of or response to stereotype threat. 
The survey questionnaire used in these studies was expressly designed to minimize concern by potential participants of an inadvertent breach of anonymity. As such, it is impossible to parse out responses to the motivation question by whether the institution with which they are affiliated is or is not coeducational, and if it is not, whether its student body is male or female. Indeed, the numbers of participants and of single sex schools involved would likely preclude this analysis in any case. But this would also be an important point for subsequent studies, as the construction of an effective model for building acceptance of women in leadership may differ among these kinds of institutions. Similarly, the number of respondents to the survey was sufficiently small as to preclude parsing responses out in each of the four cohorts by whether or not a school had a particular religious affiliation.

The survey did not ask the race of the respondent, as I was concerned that this would engender stereotype threat and skew the survey response rate along racial lines. Because $\mathrm{HBCU}$ faculty are $60 \%$, and not $100 \%$, Black, and non-HBCU CU faculty are $76 \%$, and not $100 \%$, White, I cannot draw conclusions about Black vs. White faculty from the present studies.

Finally, I assumed that the knowledge that the "evaluator" was a White woman would mean that women responding to it would not experience reinforcement of stereotype threat by being asked for the gender with which they identify. While this may have been the case, it is possible that not only women but especially men may have been influenced in their responses by stereotype threat. Indeed, this may have been the origin of the responses from men but not from women that their choice of career programmatic area was made because it allows them to combine a career in leadership with the lifestyle and priorities they most value outside of work.

Future studies could use information from institutional and national organizational databases rather than institutional websites. They could design surveys to look for similarities and differences in professional foci between Black and White faculty at HBCUs. Future studies could also examine professional foci of faculty at other racially-focused institutions, such as the Tribal Colleges and Universities (that serve Native American and Alaskan communities) or HBCUs in the U.S. Virgin Islands (that serve Black students in communities in which they are a numerical majority population). 
Acknowledgements The author is grateful for the time and effort of the respondents to the survey designed for and used in this research.

\section{References}

Agosto, V. \& Roland, E. (2018). Intersectionality and educational leadership: A critical review. Review of Research in Education, 42, 255285. DOI: 10.3102/0091732X18762433

Amemiya, J. \& Wang, M.-T. (2018). African American adolescents' gender and perceived school climate moderate how academic coping relates to achievement. Journal of School Psychology, 69, 127-142. DOI: 10.1016/j. jsp.2018.05.001

Bismark, M., Morris, J., Thomas, L., Loh, E., Phelps, G., \& Dickinson, H. (2015). Reasons and remedies for under-representation of women in medical leadership roles: a qualitative study from Australia. British Medical Journal Open, 5, eoo9384. DOI: 10.1136/bmjopen-2015-009384

Black Student Achievement Program. (2015). HBCU Facts. https://www. hcpss.org/f/schools/bsap/hbcu-facts-figures.pdf

Brauss, M. R., Lin, X., \& Baker, B. A. (2016). A gender comparison of HBCUs and PWIs in the Southeast. Women's Leadership Inst., Auburn University.

Brookfield, S. (2001). Repositioning ideology critique in a critical theory of adult learning. Adult Education Quarterly, 52, 7-22.

Center for Changing Our Campus Culture. (2017). A culturally specific perspective: The HBCU story. http://changingourcampus.org/wpcontent/uploads/2017/02/HBCU-Story-Final-2-21-17.pdf

Crenshaw, K. W. (1988). Race, reform, and retrenchment: Transformation and legitimation in antidiscrimination law. Harvard Law Review, 101, 1331-1387. DOI: 10.2307/1341398

Dawson-Smith, K. (2006). White Faculty at Historically Black Colleges and Universities. University of New Orleans Theses and Dissertations. 1044. https://scholarworks.uno.edu/td/1044

Eagly, A. H. \& Johannesen-Schmidt, M. C. (2001). The leadership styles of women and men. Journal of Social Issues, 57, 781-797. DOI: 10.1111/0022-4537.00241 
Fassiotto, M., Hamel, E. O., Ku, M., Correll, S., Grewal, D., Lavori, P., Periyakoil, V. J., Reiss, A., Sandborg, C., Walton, G., Winkleby, M., \& Valentine, H. (2016) Women in academic medicine: measuring stereotype threat among junior faculty. Journal of Women's Health, 25, 292-298. DOI: 10.1089/jwh.2015.5380

Fuller, K. (2018). New lands, new languages: Navigating intersectionality in school leadership. Frontiers in Education, 3, 25. DOI: 10.3389/ feduc.2018.00025

Garcia-Ael, C., Cuadrado, I., \& Molero, F. (2018). The effects of occupational status and sex-typed jobs on the evaluation of men and women. Frontiers in Psychology, 9, 1170. DOI: 10.3389/ fpsyg.2018.01170

Gasman, M. (2012). The changing face of Historically Black Colleges and Universities (p. 6). Philadelphia, PA: University of Pennsylvania, Graduate School of Education, Center for MSIs.

Gasman, M., Smith, T., Ye, C., \& Nguyen, T.-H. (2017). HBCUs and the production of doctors. American Institute of Mathematical Sciences Public Health, 4, 549. DOI: 10.3934/publichealth.2017.6.579

Gillenwalters, E. \& Martinez, N. (2017). Review of gender and racial diversity in radiation protection. Health Physics, 112, 384-391. DOI: 10.1097/HP.ooooooooooooo640

HBCU Lifestyle. (2019). List of HBCUs by state. https://hbculifestyle.com/ list-of-hbcu-schools/

Hannum, K. M., Muhly, S. M., Shockley-Zalabak, P. S., \& White, J. S. (2015). Women leaders within higher education in the United States: supports, barriers, and experiences of being a senior leader. Advancing Women in Leadership, 35, 65-75. DOI: 10.18738/awl.v35io.129

Henderson, D. X., Martin, P. P., \& Harris, K. (2019). A case study on undergraduate community psychology at a Historically Black College and University (HBCU). Global Journal of Community Psychology Practice, 10, 1.

Jones, S. R. (2016). Authenticity in leadership: Intersectionality of identities. Developing Culturally Relevant Leadership Learning: New Directions for Student Leadership, 152, 23-34. DOI: 10.1002/yd.20206

Kifle, T. \& Desta, I. H. (2012). Gender differences in domains of job satisfaction: evidence from doctoral graduates from Australian universities. Economic Analysis and Policy, 42, 319. DOI: 10.1016/ So313-5926(12)50032-9 
Laurin, R. (2019). An investigation of the roles of group identification, perceived ability, and evaluative conditions in stereotype threat experiences. Psychological Reports. DOI: 10.1177/0033294119884013

Lomax, ML. (2006). Historically black colleges and universities: bringing a tradition of engagement into the twenty-first century. Journal of Higher Education Outreach and Engagement, 11, 5.

Mader, E. M., Rodríguez, J. E., Campbell, K. M., Smilnak, T., Bazemore, A. W., Petterson, S., \& Morley, C. P. (2016). Status of underrepresented minority and female faculty at medical schools located within Historically Black Colleges and in Puerto Rico. Medical Education Online, 21, 29535. DOI: 10.3402/meo.v21.29535

Mathewson, E. (2017). Female presidents are playing critical roles in the survival of HBCUs. $H B C U$ Lifestyle, https://theundefeated.com/features/, female-presidents-are-playing-critical-roles-in-the-survival-of-hbcus/

Mayberry, K. R. (2018). African American women leaders, intersectionality, and organizations. Minneapolis, MN: Walden University ScholarWorks. https://scholarworks.waldenu.edu/ dissertations

Miller, E. (2017). Professional women: a gendered look at inequality in the US workforce. AFL-CIO Fact Sheet, https://dpeaflcio.org/programspublications/issue-fact-sheets/professional-women-a-gendered-lookat-occupational-obstacles-and-opportunities/

National Center for Education Statistics (n.d.). Fast facts: Historically Black Colleges and Universities, https://nces.ed.gov/fastfacts/display. asp?id $=667$

Powers, B. W., White, A. A., Oriol, N. E., \& Jain, S. H. (2016). Raceconscious professionalism and African-American representation in academic medicine. Academic Medicine, 91, 913-915. DOI: 10.1097/ ACM.0ooooooooooo1074

Renzulli, L. A., Grant, L., \& Kathuria, S. (2006). Race, gender, and the wage gap: Comparing faculty salaries in predominantly White and Historically Black Colleges and Universities. Gender \& Society, 2O, 491510. DOI: 10.1177/0891243206287130

Richardson, A. \& Loubier, C. (2008). Intersectionality and leadership. International Journal of Leadership Studies, 3, 142-161. 
Rodriguez, J. E., Lopez, I. A., Campbell, K. M., \& Dutton, M. (2017). The role of Historically Black College and University Medical Schools in academic medicine. Journal of Health Care for the Poor \& Underserved, 28, 266-278. DOI: 10.1353/hpu.2017.0022

Roland, E. (2018). Understanding intersectionality to promote social justice in educational leadership: Review of JCEL cases. Intersections: Critical Issues in Education, 2, 3-18.

Runyan, A. S. (2018). What is intersectionality and why is it important? Academe, https://www.aaup.org/article/what-intersectionality-andwhy-it-important\#.Xd8jgehKg2X

Schor, N. F. (2018). The decanal divide: women in decanal roles at U.S. medical schools. Academic Medicine, 93, 237-240. DOI: 10.1097/ ACM.0ooooooooooo1863

Schor, N. F. (2019). Women in medical school leadership positions: Implications for research. Annals of Neurology, 85, 789-792. DOI: 10.1002/ana.25478

Settles, I. H., Pratt-Hyatt, J. S., \& Buchanan, N. T. (2008). Through the lens of race: Black and White women's perceptions of womanhood. Psychology of Women Quarterly, 32, 454-468. DOI: 10.1111/j.1471-6402.2008.00458.x

Shepherd, S. (2017). Why are there so few female leaders in higher education: a case of structure or agency? Management in Education, 31, 82-87. DOI: 10.1177/o892020617696631

Smith, J. S., LaFrance, M., \& Dovidio, J. F. (2017). Categorising intersectional targets: An "either/and" approach to race and gender-emotion congruity. Cognition \& Emotion, 31, 83-97. DOI: 10.1080/02699931.2015.1081875

Spencer, S. J., Logel, C., \& Davies, P. G. (2016). Stereotype threat. Annual Reviews of Psychology, 67, 415-437. DOI: 10.1146/ annurev-psych-073115-103235

Strothers, A. (2014). Chapter 5: White faces in Black places: HBCUs and the White faculty experience. In M. Gasman and F. Commodore (Eds.) Opportunities and Challenges at Historically Black Colleges and Universities (pp. 75-88). New York: Palgrave Macmillan.

Stuart, R. (2012). HBCUs facing challenges amid efforts to stay financially viable and competitive. Diverse Issues in Higher Education, https:// diverseeducation.com/article/48471/ 
Sullivan, K.., Guzman, A. S., \& Ghaffari, D. (2019). The relationship between social identity, stereotype threat, and academic success among prenursing students. Nursing Education Perspectives, 40, E16-E18. DOI: 10.1097/01.NEP.ooooooooooooo578

ten Brummelhuis, L. \& Greenhaus, J. H. (2019). When juggling work and family, women offer more emotional support than men. Harvard Business Review, https://hbr.org/2019/03/research-when-jugglingwork-and-family-women-offer-more-emotional-support-than-men

Tomar, D. A. (2019). The history of Historically Black Colleges. The Quad, https://thebestschools.org/magazine/historically-black-colleges/ van Veelen, R., Derks, B., \& Endedijk, M. D. (2019). Double trouble: how being outnumbered and negatively stereotyped threatens career outcomes of women in STEM. Frontiers in Psychology, 10, 150. DOI: 10.3389/fpsyg.2019.00150 


\section{Supplemental Table 1}

Survey Distributed via www.surveymonkey.com to Academic Leaders $(n=1,081)$ at HBCUs and Comparator CUs

Note: Survey responses were digitally rendered anonymous before receipt.

\section{Determinants of Primary Focus of Leadership Roles of Faculty}

The questions below are part of a study aimed at identifying some of the factors that determine the choice of primary career programmatic focus of college and university faculty in major leadership positions. The results will be collected, tabulated, and analyzed in a fashion that precludes linkage of responses to specific individuals (i.e., in anonymized fashion). Some of my prior work in this area can be found at:

Schor, NF. Ann Neurol. 2019 Jun;85(6):789-792.

Schor, NF. Acad Med. 2018 Feb;93(2):237-240.

I am grateful for your responses and your spending time entering them into the brief questionnaire below. Many thanks.

1. As what gender do you identify?

2. With what type of college or university are you affiliated?
a. Nonsectarian liberal arts
b. Nonsectarian vocational
c. Religious liberal arts
d. Religious vocational
e. Community (2-year) college

3. What is your current administrative title?
a. President/Chancellor
b. Vice President
c. Provost
d. Vice Provost
e. Other 
4. What is the primary programmatic focus of your administrative leadership role?
a. General
b. Research
c. Education
d. Faculty Affairs/Faculty Development
e. Finance
f. Policy/Government Relations
g. Public Relations/Community Affairs
h. International Relations
i. Diversity/Inclusion
j. Marketing
k. Information Technology
1. Other

5. Is the college with which you are affiliated a Historically Black College or University?
a. Yes
b. No

6. Which one of the following statements best approximates the single most important (to you) reason you made the area you checked the primary programmatic focus of your administrative role?
a. This is an area about which I am passionate, in which I am spe- cifically trained, and/or to which I have chosen to dedicate a sig- nificant fraction of my career.
b. The leadership of my institution identified a gap in this area and asked that I fill it.
c. This is an area in which effective leadership can readily be com- bined with the lifestyle and priorities I most value outside of work.
d. This is an area in which many others of my gender are engaged and accepted by a diverse array of peers.
e. Other (please specify) 


\section{Supplemental Table 2}

Characteristics of Colleges and Universities (CU) Represented among Historically Black (HB) and Comparator Institutions.

\begin{tabular}{lcc} 
& HBCU & Comparator CU \\
\hline \# of Schools & 102 & 102 \\
\% Public & 48 & 48 \\
\% 2-Year Degrees Only & 11 & 14 \\
\% Religion-affiliated Co-educational School & 25 & 25 \\
\% Religion-affiliated Women's School & 0 & 1 \\
\% Religion-affiliated Men's School & 0 & 1 \\
\% Secular Women's School & 2 & 2 \\
\% Secular Men's School & 0 & 0 \\
Student Enrollment (mean \pm SEM) & $3,226 \pm 297$ & $4,009 \pm 392$ \\
\% Female Students* & 62 & 56 \\
\% Black Students* & 76 & 14 \\
\hline
\end{tabular}

Note: * National Center for Education Statistics. https://nces.ed.gov/, accessed 4/5/2020. 